\title{
Expression of miR-199a-3p in human adipocytes is regulated by free fatty acids and adipokines
}

\author{
NAN GU ${ }^{1,2^{*}}$, LIANGHUI YOU ${ }^{1 *}$, CHUNMEI SHI $^{1}$, LEI YANG $^{1}$, LINGXIA PANG $^{1}$, \\ XIANWEI CUI ${ }^{1}$, CHENBO JI ${ }^{1}$, WEN ZHENG ${ }^{3}$ and XIRONG GUO ${ }^{1,2}$ \\ ${ }^{1}$ Nanjing Maternity and Child Health Care Institute, \\ Nanjing Maternity and Child Health Care Hospital Affiliated With Nanjing Medical University, \\ Nanjing, Jiangsu 210004; ${ }^{2}$ Institute of Pediatrics, Nanjing Medical University, Nanjing, Jiangsu 210029; \\ ${ }^{3}$ Maternity and Child Health Hospital of Yancheng, Yancheng, Jiangsu 224002, P.R. China
}

Received December 23, 2015; Accepted May 17, 2016

DOI: $10.3892 / \mathrm{mmr} .2016 .5379$

\begin{abstract}
Obesity is associated with a notable risk for disease, including risk of cardiovascular disorders, type 2 diabetes mellitus (T2DM) and hypertension. Adipose tissue modulates the metabolism by releasing free fatty acids (FFAs) and adipokines, including leptin, resistin, tumor necrosis factor- $\alpha$ (TNF- $\alpha$ ) and interleukin 6 (IL-6). Altered secretion patterns of FFAs and adipokines have been demonstrated to result in obesity-associated insulin resistance (IR) and inflammatory responses. MicroRNA-199a-3p (miR)-199a-3p expression is significantly induced in differentiated human adipose-derived mesenchymal stem cells and indicates the association with T2DM. However, the association between miR-199a-3p levels in adipocytes and obesity-associated IR, as well as inflammatory responses remains to be elucidated. The present study observed an elevation of miR-199a-3p expression level in mature human adipocytes (visceral) compared with pre-adipocytes. In addition, miR-199a-3p expression was higher in visceral adipose deposits from obese subjects. FFA, TNF- $\alpha$, IL-6 and leptin significantly induced miR-199a-3p expression in mature human adipocytes, while resistin had the opposite effect. miR-199a-3p may represent a factor in the modulation of obesity-associated IR and inflammatory responses.
\end{abstract}

Correspondence to: Professor Xirong Guo, Nanjing Maternity and Child Health Care Institute, Nanjing Maternity and Child Health Care Hospital Affiliated With Nanjing Medical University, 123 Mochou Road, Nanjing, Jiangsu 210004, P.R. China

E-mail:xrguo@njmu.edu.cn

Mr. Wen Zheng, Maternity and Child Health Hospital of Yancheng, 34 Yu Long West Road, Yancheng, Jiangsu 224002, P.R. China

E-mail: 113882434@qq.com

*Contributed equally

Key words: miR-199a-3p, adipocytes, adipokines, FFAs, obesity

\section{Introduction}

Obesity is a serious issue worldwide, it is associated with a marked risk for disease, including risk of cardiovascular disorders, type 2 diabetes mellitus (T2DM) and hypertension (1-3). The etiology of obesity is an imbalance between energy intake and energy consumption (4). As a type of endocrine organ, adipose tissue contributes to the release of metabolites, including free fatty acids (FFAs), leptin, resistin, tumor necrosis factor- $\alpha$ (TNF- $\alpha$ ) and interleukin $6(5,6)$. The changes in adipose tissue secretion have been well-illustrated to associate obesity with IR and inflammatory responses $(7,8)$, however, the detailed underlying mechanism requires further elucidation.

MicroRNAs (miRNAs) are a class of non-coding RNAs (length, 19-22 nt) that post-transcriptionally modulate gene expression via specifically binding to the 3 '-untranslated regions (3'-UTRs) of target mRNAs (9). Previous studies have suggested that miRNAs are important in cellular differentiation and development $(10,11)$, tumorigenesis $(12,13)$, and metabolic diseases (14). miRNAs, including miR-143 (15), miR-146b (16), and miR-378/378* (17) have also been demonstrated to modulate adipocyte differentiation in mouse and human cell line models. Furthermore, miRNA dysregulation has been reported in human obesity and IR $(18,19)$.

miRNA-199a-3p (miR-199a-3p) is a conserved miRNA in mice and humans, it has been reported to potentially be important in T2DM. A meta-analysis performed by Zhu and Leung (20) observed that miR-199a-3p expression was dysregulated in T2DM patients, presenting a pancreasand liver- specific disturbance. In addition, upregulation of miR-199a-3p expression occurred in islet cells from mouse models of T2DM (21). Our previous study identified miR-199a-3p was highly induced in differentiated human adipose-derived mesenchymal stem cells (hMSCs-Ad) (22). However, the association between the differential expression of miR-199a-3p in adipocytes and obesity-associated IR and inflammatory responses remains to be elucidated.

In the present study, increased expression of miR-199a-3p in mature human adipocytes (visceral) was observed compared with pre-adipocytes. In addition, miR-199a-3p expression was 
higher in visceral adipose tissues from obese subjects. FFAs, TNF- $\alpha$, IL-6 and leptin were observed to significantly induce miR-199a-3p expression in mature human adipocytes, while resistin had the opposite effect. miR-199a-3p may exert an effect in modulation of obesity-associated IR and inflammatory reactions.

\section{Materials and methods}

Human subjects. Visceral white adipose tissue samples were obtained from 12 subjects undergoing surgery for various disorders at Nanjing Maternity and Child Health Care Hospital Affiliated with Nanjing Medical University. Patients did not have any notable conditions, including malignant tumors, severe genetic diseases, infectious disorders or autoimmune dysregulation. Based on body mass index (BMI), patients were defined as normal subjects with a BMI of $18-24 \mathrm{~kg} / \mathrm{m}^{2}$ $(n=6)$ and obese subjects with a BMI of $>28 \mathrm{~kg} / \mathrm{m}^{2}(\mathrm{n}=6)$. Biopsies were maintained in RNAlater RNA Stabilization reagent (Qiagen, Inc., Valencia, CA, USA) and maintained at $-80^{\circ} \mathrm{C}$ for total RNA extraction. Prior to participation in the present study, all patients provided written informed consent. The current study was approved by the Ethics Committee of Nanjing Maternity and Child Health Care Hospital Affiliated to Nanjing Medical University (Nanjing, China).

Cell culture. Human pre-adipocytes from visceral (omental) adipose were purchased from ScienCell Research Laboratories (Carlsbad, CA, USA). Pre-adipocytes were maintained and induced to differentiate as previously described (23). Briefly, pre-adipocyte differentiation medium (cat. no. 7221; ScienCell Research Laboratories) containing fetal bovine serum (5\%), growth supplement (1\%) and penicillin/streptomycin solution (1\%) was used as basal medium for cell expansion. Upon reaching confluence, cells were exposed to induction medium for the first 4 days and shifted to differentiation medium until the appearance of mature lipid droplets was observed (15 days). The induction medium contained pre-adipocyte medium without serum, supplemented with $500 \mu \mathrm{M}$ 3-isobutyl-L-methylxanthine (Sigma-Aldrich, St. Louis, MO, USA), $100 \mathrm{nM}$ dexamethasone (Sigma-Aldrich), $50 \mathrm{nM}$ insulin (Sigma-Aldrich) and $100 \mu \mathrm{M}$ rosiglitazone (Sigma-Aldrich). The differentiation medium was serum-free pre-adipocyte medium containing $50 \mathrm{nM}$ insulin.

Oil red $O$ staining. Following induction on day 4 and day 15, adipocytes were washed with phosphate-buffered saline (PBS) three times. They were fixed in $4 \%$ paraformaldehyde for 30 min prior to washing again with PBS. Lipid accumulation was measured by staining with $0.2 \%(\mathrm{~m} / \mathrm{v})$ oil red O (Sigma-Aldrich) dissolved in isopropanol for $30 \mathrm{~min}$ at $37^{\circ} \mathrm{C}$. The cells were examined by fluorescence microscopy (ImagingA1; Carl Zeiss AG, Oberkochen, Germany).

Treatment of adipocytes with adipokines and FFAs. After 15 days induction of differentiation, $>85 \%$ of the adipocytes exhibited lipid droplet accumulation. Following serum starvation for $12 \mathrm{~h}$, the human adipocytes were treated with a $1 \mathrm{mM}$ FFA cocktail and adipokines, including $10 \mathrm{ng} / \mathrm{ml}$ TNF- $\alpha$ (Sigma-Aldrich), 30 ng/ml IL-6
(Sigma-Aldrich), $100 \mathrm{ng} / \mathrm{ml}$ leptin (Sigma-Aldrich) and $60 \mathrm{ng} / \mathrm{ml}$ resistin (Sigma-Aldrich) for different durations (4, 8 and $24 \mathrm{~h}$ ) (24-26), then cells were treated with TRIzol (Invitrogen; Thermo Fisher Scientific, Inc., Waltham, MA, USA) for the following experiment.

$R N A$ extraction and reverse transcription-quantitative polymerase chain reaction $(R T-q P C R)$. Total RNA was extracted from adipose tissues and mature adipocytes using an RNeasy Mini kit (Qiagen). Concentration and purity of extracted total RNA were quantified using a Nanodrop spectrophotometer 2000 (Thermo Fisher Scientific, Inc.). For analysis of mature miRNA quantification, $200 \mathrm{ng}$ total RNA was reverse transcribed using TaqMan miRNA Reverse Transcriptase kit (Applied Biosystems; Thermo Fisher Scientific, Inc.) and the following temperature conditions: $16^{\circ} \mathrm{C}$ for $30 \mathrm{~min}, 42^{\circ} \mathrm{C}$ for $30 \mathrm{~min}, 85^{\circ} \mathrm{C}$ for $5 \mathrm{~min}, 4^{\circ} \mathrm{C}$. qPCR was performed using TaqMan Universal Master Mix II, no UNG (Thermo Fisher Scientific, Inc.) and commercial primers for miR-199a-3p, miR-103 and U6 (cat. no. A25576; Thermo Fisher Scientific, Inc.) on an ABI 7500 real-time PCR system (Applied Biosystems; Thermo Fisher Scientific, Inc.) according to the manufacturer's protocols as previously described (16). Briefly, samples were incubated at $95^{\circ} \mathrm{C}$ for $10 \mathrm{~min}$ for an initial denaturation, followed by 40 cycles consisting of incubation at $95^{\circ} \mathrm{C}$ for $15 \mathrm{sec}$ and $60^{\circ} \mathrm{C}$ for $1 \mathrm{~min}$. The expression of miR-199a-3p was normalized to U6 small nucleolar RNA or miR-103 expression (27) and the fold change was calculated using the $2^{-\Delta \Delta \mathrm{Cq}}$ method (28).

Statistical analysis. The data are presented as mean \pm standard deviation. Differences between groups were analyzed by Student's two-tailed t-test when only two groups were present or by one way analysis of variance and Bonferroni correction for multiple comparisons. $\mathrm{P}<0.05$ was considered to indicate a statistically significant difference.

\section{Results}

Expression of miR-199a-3p increased during human adipocyte differentiation. For adipocyte differentiation, cells were grown to confluence as day 0 (Fig. 1A). Adipocytes differentiated for 4 and 15 days exhibited oil red $\mathrm{O}$ staining (Fig. $1 \mathrm{~B}$ and $\mathrm{C}$ ). After 15 days induction of differentiation, $>80 \%$ of the adipocytes were observed with lipid droplet accumulation. miR-199a-3p expression between pre-adipocytes (day 0) and mature adipocytes (day 15) was evaluated by RT-qPCR. It was demonstrated the expression level of miR-199a-3p in mature adipocytes increased $\sim 3.4$ fold change compared with that in human pre-adipocytes (Fig. 2A; P<0.05).

Upregulation of miR-199a-3p was observed in visceral fat tissues from obese human subjects. To determine the role of miR-199a-3p within obese subjects, miR-199a-3p expression levels were measured in the visceral fat tissues of lean and obese human subjects. Visceral fat tissues samples were acquired from 6 lean and 6 obese human subjects (Table I). RT-qPCR results indicated the miR-199a-3p expression levels were upregulated in the visceral fat tissue samples from obese subjects (Fig. 2B; $\mathrm{P}<0.05$ ). 
A

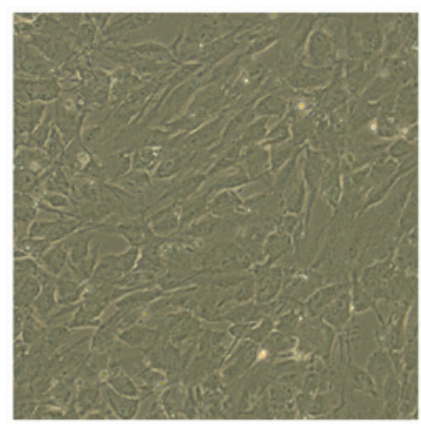

Day 0
B

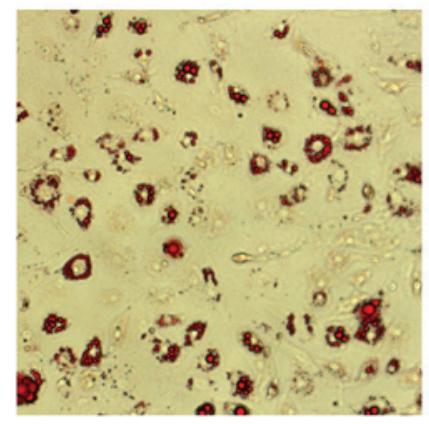

Day 4

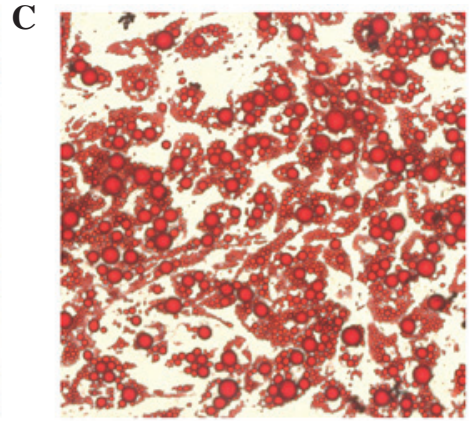

Day 15

Figure 1. Prior to and following differentiation of human pre-adipocytes. Representative micrograph of human pre-adipocytes on (A) day 0, and oil red O staining of lipid droplets accumulation in differentiated adipocytes on (B) day 4 and (C) day 15.

A

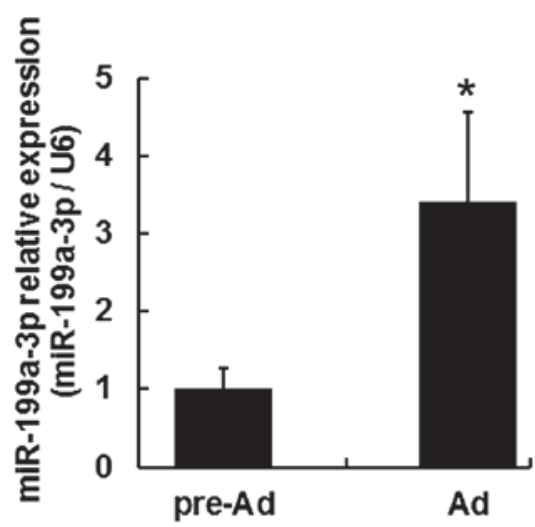

B

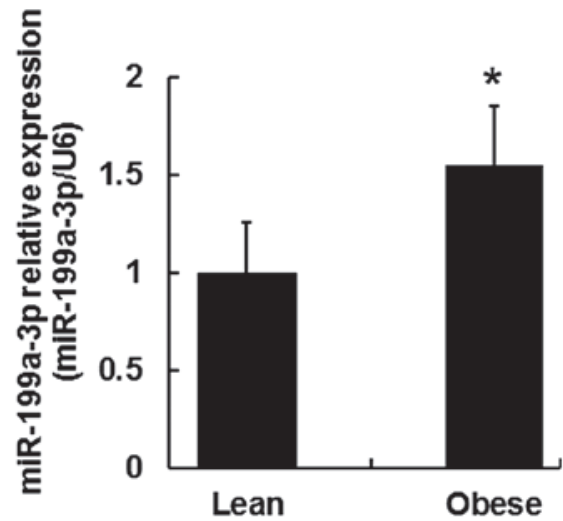

Figure 2. Upregulation of miR-199a-3p expression during human adipocyte differentiation and in visceral fat tissues from obese human subjects. (A) Human pre-Ad cells and mature Ad were harvested respectively at the differentiation of day 0 and day 15. (B) miR-199a-3p expression was detected in visceral fat tissues between lean $(n=6)$ and obese $(n=6)$ subjects $(B)$. miR-199a-3p expression was detected by reverse transcription-quantitative polymerase chain reaction assays and normalized to U6. Data are presented as the mean \pm standard deviation of three separate experiments. ${ }^{*} \mathrm{P}<0.05$ vs. vs. the pre Ad or lean group. miR, microRNA; pre-Ad, pre-adipocytes; Ad, adipocytes.

Table I. Variables between obese and lean subjects.

\begin{tabular}{lcc}
\hline $\begin{array}{l}\text { Variable } \\
(\text { mean } \pm \mathrm{SD})\end{array}$ & $\begin{array}{c}\text { Obese group } \\
(\mathrm{n}=6)\end{array}$ & $\begin{array}{c}\text { Lean group } \\
(\mathrm{n}=6)\end{array}$ \\
\hline Age (year) & $50.33 \pm 18.27$ & $46.23 \pm 11.41^{\mathrm{a}}$ \\
Weight $(\mathrm{kg})$ & $85.50 \pm 20.95$ & $56.50 \pm 10.28^{\mathrm{b}}$ \\
Height $(\mathrm{m})$ & $1.64 \pm 0.04$ & $1.69 \pm 0.06^{\mathrm{a}}$ \\
BMI $\left(\mathrm{kg} / \mathrm{m}^{2}\right)$ & $31.38 \pm 6.30$ & $20.42 \pm 3.52^{\mathrm{b}}$ \\
\hline
\end{tabular}

${ }^{\mathrm{a}} \mathrm{P}>0.05 ;{ }^{\mathrm{b}} \mathrm{P}<0.05$. SD, standard deviation; BMI, body mass index.

Leptin initially increased and resistin decreased miR-199a-3p expression levels in human differentiated adipocytes. To investigate the effect of leptin and resistin on miR-199a-3p, mature adipocytes, following 15 days induced differentiation, were treated with $100 \mathrm{ng} / \mathrm{ml}$ leptin and collected at 4, 8 and $24 \mathrm{~h}$. Cells without treatment served as the control group (defined as $0 \mathrm{~h}$ ). miR-103 and U6 served as reference genes for normalization in order to obtain consistent results. It was observed that leptin significantly stimulated miR-199a-3p expression at $4 \mathrm{~h}$ $(\mathrm{P}<0.01)$ but this effect decreased over time (Fig. $3 \mathrm{~A}$ and $\mathrm{B}$ ). By contrast, exposure of mature adipocytes to $60 \mathrm{ng} / \mathrm{ml}$ resistin resulted in a significant decrease in miR-199a-3p expression at $8 \mathrm{~h}(\mathrm{P}<0.05$ when normalized to $\mathrm{U} 6, \mathrm{P}<0.01$ when normalized to miR-103; Fig. 3C and D).

TNF- $\alpha$ and IL- $\beta$ upregulated expression of miR-199a-3p in human mature adipocytes. To investigate the response of miR-199-3p to inflammatory cytokines, including TNF- $\alpha$ and IL- $\beta$, mature human adipocytes that had been differentiated for 15 days were treated with $10 \mathrm{ng} / \mathrm{ml} \mathrm{TNF}-\alpha$ and $30 \mathrm{ng} / \mathrm{ml} \mathrm{IL-} \beta$ and harvested at different time points (4, 8 and $24 \mathrm{~h})$. Cells without treatment served as the control group (defined as $0 \mathrm{~h}$ ). miR-103 and U6 expression were used as reference genes for normalization in order to obtain consistent results. RT-qPCR results indicated that miR-199a-3p expression was gradually increased when mature human adipocytes were exposed to $10 \mathrm{ng} / \mathrm{ml}$ TNF- $\alpha$, reaching a maximum at $8 \mathrm{~h}(\mathrm{P}<0.01)$. The upregulation was sustained to $24 \mathrm{~h}(\mathrm{P}<0.05$; Fig. $4 \mathrm{~A}$ and $\mathrm{B})$. IL- $\beta$ treatment exhibited a similar trend in mir-199a-3p expression $(\mathrm{P}<0.01$ at $4 \mathrm{~h}, \mathrm{P}<0.01$ when normalized to $\mathrm{U} 6$ and $\mathrm{P}<0.001$ when normalized to miR-103 at $8 \mathrm{~h}, \mathrm{P}<0.001$ when normalized to U6 and $\mathrm{P}<0.05$ when normalized to miR-103; Fig. 4C and D).

FFAs increased expression of miR-199a-3p in human mature adipocytes. To investigate the effect of FFAs on miR-199a-3p 
A

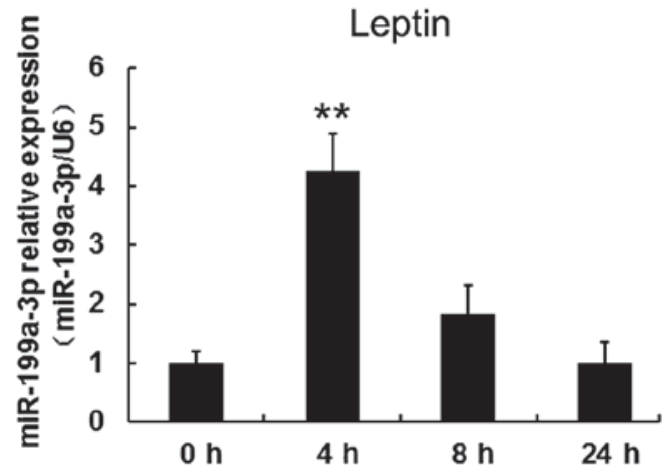

C

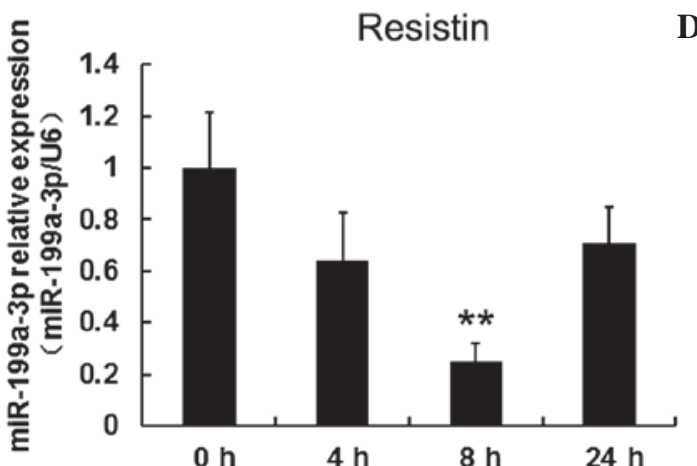

B 5

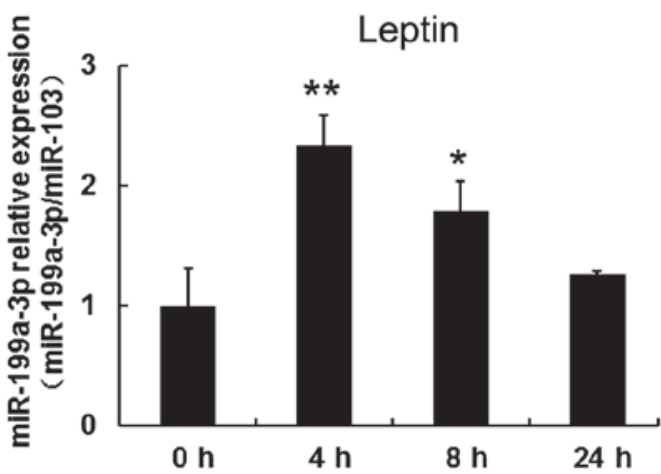

D 등

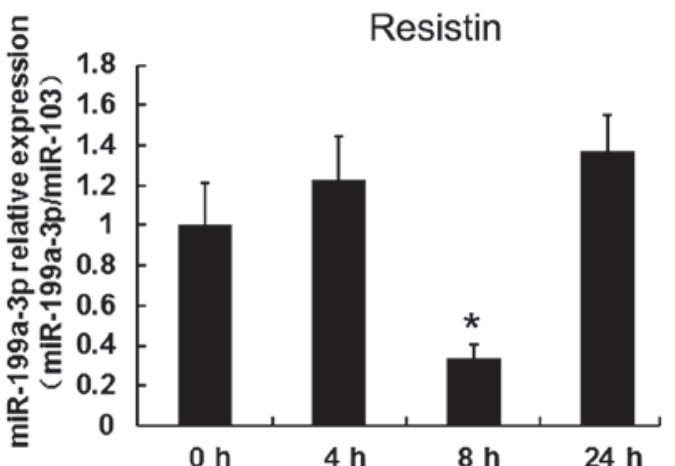

Figure 3. Expression levels of miR-199a-3p are differentially regulated by leptin and resistin exposure. Following exposure of human mature adipocytes to (A and B) $100 \mathrm{ng} / \mathrm{ml}$ leptin or (C and D) $60 \mathrm{ng} / \mathrm{ml}$ resistin at different time points $(4,8$ and $24 \mathrm{~h})$, reverse transcription-quantitative polymerase chain reaction was adopted for miR-199a-3p expression. Cells without treatment were served as the control group (defined as 0 h). U6 and miR-103 expression served as internal controls for normalization. Values are presented as the mean \pm standard deviation of three separate experiments. ${ }^{*} \mathrm{P}<0.05$; ${ }^{* * *} \mathrm{P}<0.01 \mathrm{vs}$. the $0 \mathrm{~h}$ group. miR, microRNA.

A

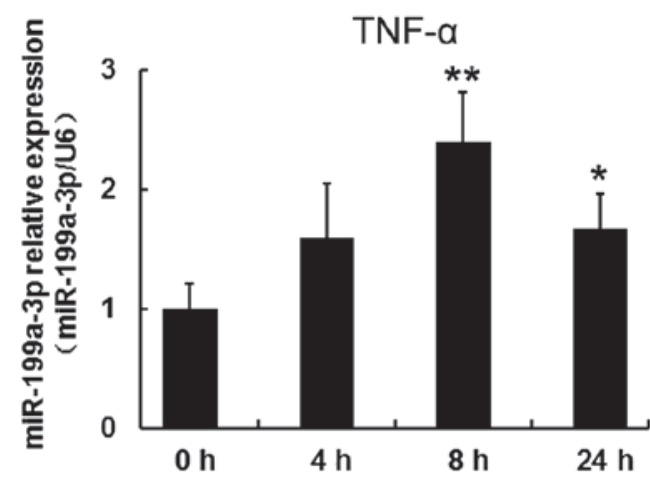

C

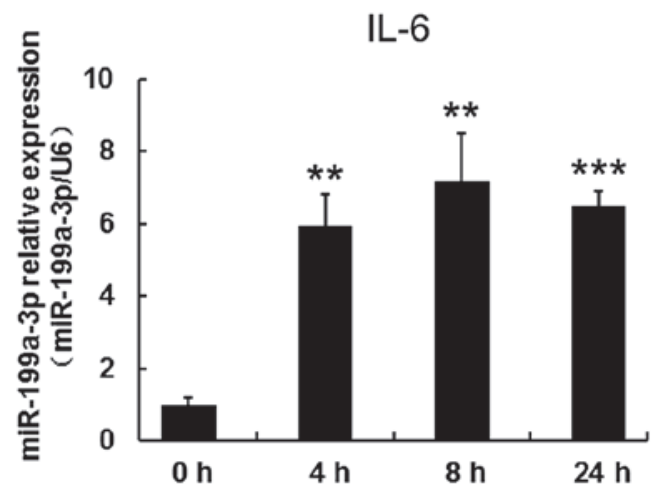

B

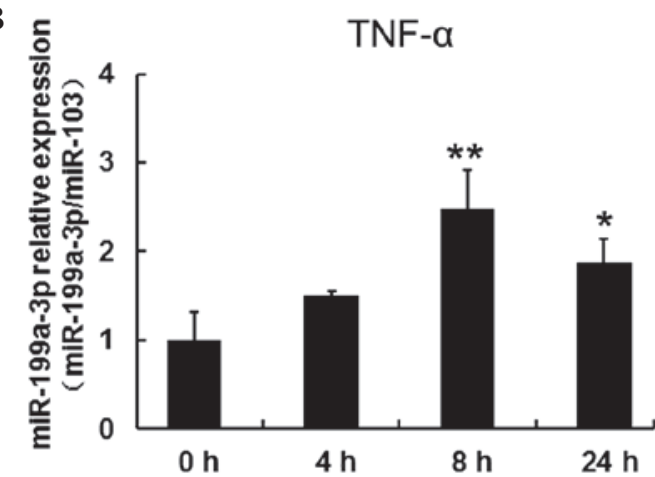

D

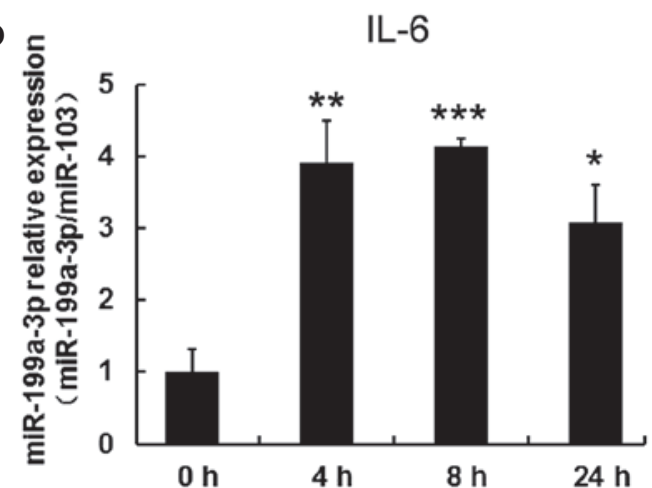

Figure 4. Inflammatory cytokines, TNF- $\alpha$ and IL-6, increased miR-199a-3p expression in human mature adipocytes. Reverse transcription-quantitative polymerase chain reaction was used to analyze miR-199a-3p expression in human mature adipocytes cultured with (A and B) $10 \mathrm{ng} / \mathrm{ml} \mathrm{TNF}-\alpha$ or (C and D) $30 \mathrm{ng} / \mathrm{ml}$ IL-6 at different time points (4, 8 and $24 \mathrm{~h}$ ). Cells without treatment served as the control group (defined as $0 \mathrm{~h}$ ). U6 and miR-103 expression served as internal controls for normalization. Values are presented as the mean \pm standard deviation of three separate experiments. ${ }^{*} \mathrm{P}<0.05 ;{ }^{* * *} \mathrm{P}<0.01$; ${ }^{* * *} \mathrm{P}<0.001$ vs. the 0 h group. miR, microRNA; TNF- $\alpha$, tumor necrosis factor- $\alpha$; IL, interleukin. 
A

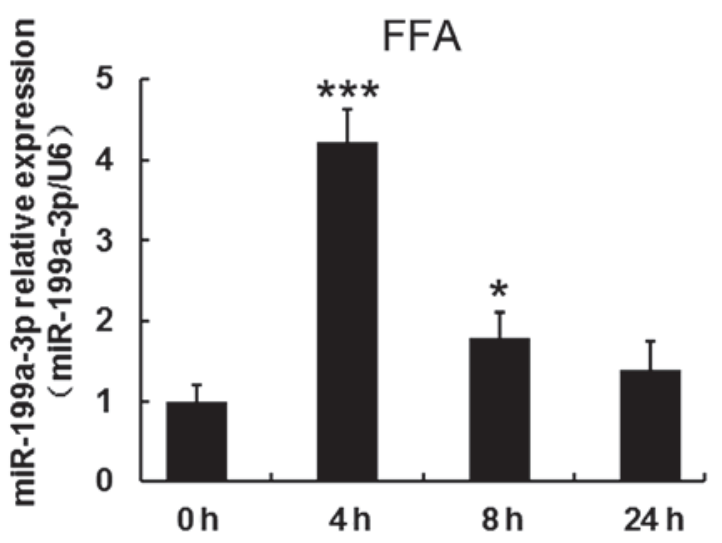

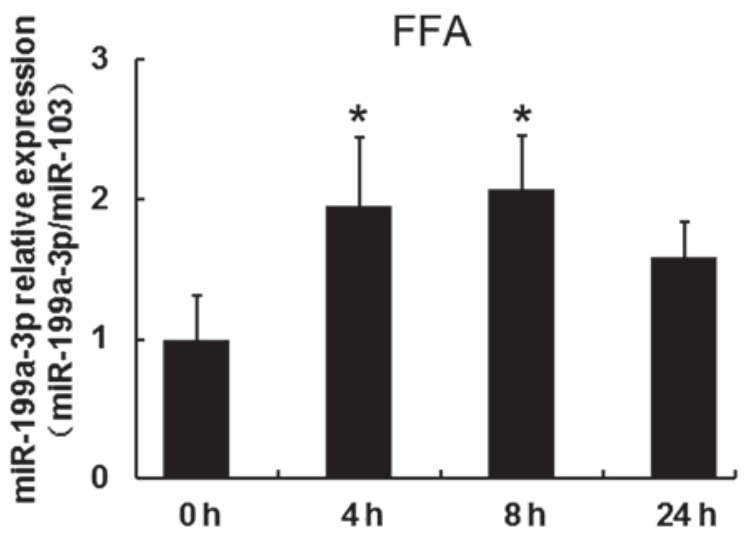

Figure 5. Effect of FFA on miR-199a-3p expression in human mature adipocytes. Reverse transcription-quantitative polymerase chain reaction was used to analyze miR-199a-3p expression in human mature adipocytes cultured with $1 \mathrm{mM}$ FFAs at different time points (4, 8 and $24 \mathrm{~h}$ ). Cells without treatment served as the control group (defined as $0 \mathrm{~h}$ ). miR-199a-3p expression was normalized to (A) U6 or (B) miR-103 expression. Values are expressed as the mean \pm standard deviation of three separate experiments. ${ }^{*} \mathrm{P}<0.05 ;{ }^{* * *} \mathrm{P}<0.001$ vs. the 0 h group. FFA, free fatty acid; miR, microRNA.

expression, mature human adipocytes following 15 days induced differentiation, were treated with $1 \mathrm{mM}$ FFA at different time points (4, 8 and $24 \mathrm{~h}$ ). Cells without treatment served as the control group (defined as $0 \mathrm{~h}$ ). To confirm the regulation by FFAs, miR-103 and U6 expression were reference genes for normalization. RT-qPCR results indicated miR-199a-3p expression was significantly increased $(\mathrm{P}<0.001$ when normalized to U6 and $\mathrm{P}<0.05$ when normalized to miR-103 at 4 h) within $8 \mathrm{~h}$, but decreased again over time (Fig. 5A and B).

\section{Discussion}

Altered adipose tissue function is observed between normal and obese individuals. The dysregulation of adipose tissue in obese subjects is commonly characterized by the following features $(6,29)$ : i) Adipocyte hypertrophy; ii) ectopic fat accumulation; and iii) adipose tissue inflammation. The alteration of fat tissue function exerts a key effect in the development of IR and T2DM (8). However, understanding of the underlying mechanisms linking obesity and adipose tissue dysfunction to IR requires further research.

miR-199a-3p, which is commonly identified as a suppressor gene, has been observed to be involved in the progression of various types of cancer, including hepatocellular carcinoma (30), osteosarcoma (31), ovarian carcinoma (32) and thyroid carcinoma (33). In addition, previous studies have demonstrated the potential implication of miR-199a-3p in T2DM $(20,21)$. However, the differential miR-199a-3p expression during adipocyte differentiation and the progression obesity has not been fully elucidated from experimental studies in animal models or in humans.

hMSCs-Ad are a well-characterized type of adult stem cell that may differentiate into adipocytes, osteoblasts and chondrocytes under various conditions (34). Use of monoclonal antibodies and cell sorting on the basis of specific markers (35), resulted in obtaining a common early precursor of MSC and adipocytes that was termed human pre-adipocyte, which differentiates into mature adipocytes under suitable stimulatory condition (36). Using pre-adipocytes for in vitro experiments is a effective strategy as they most closely resemble the physiological situation in vivo. The present study used human pre-adipocytes as a model to examine miR-199a-3p expression during differentiation and the results of the current study demonstrated miR-199a-3p expression was higher in mature adipocytes compared with pre-adipocytes. This trend was consistent with our previous study in hMSCs-Ad (22). It was also observed that the expression level of miR-199a-3p increased in the visceral fat tissue samples from obese subjects relative to the lean subjects (Fig. 2B). Further experiments are required to validate the function of miR-199a-3p in human adipocyte differentiation and the progression of obesity.

Among adipokines secreted by adipose tissue, leptin is the best characterized (37). The predominant function of leptin is to control adipose tissue growth, reduce appetite and increase energy consumption $(38,39)$. By contrast, leptin plasma concentration and mRNA expression levels in adipose tissue were elevated in obese individuals (40). The high dose of leptin levels directly results in IR in the liver and adipose tissue (41). Resistin, another adipocyte derived factor, was induced in adipogenesis and in genetic and diet-induced obesity (42). Previous studies have demonstrated the role of resistin in the modulation of the insulin signaling pathway and that resistin contributes to IR and T2DM $(43,44)$. In the present study, it was observed that exposure of mature adipocytes to $100 \mathrm{ng} / \mathrm{ml}$ leptin resulted in a significant upregulation of miR-199a-3p at $4 \mathrm{~h}$, however, this effect decreased over time. By contrast, resistin has a negative effect on miR-199a-3p expression. These observations demonstrated that miR-199a-3p was involved in obesity-associated IR.

Pro-inflammatory adipokines, including TNF- $\alpha$ and IL-6 commonly participate in different inflammatory and autoimmune diseases $(45,46)$. The level of TNF- $\alpha$ is increased in chronic obesity and it has been demonstrated to impair insulin secretion and induce IR (47). Moderate elevation of IL-6 levels has also been observed in obese individuals (48), and it may be a contributing factors in the development of obesity-associated diseases, including IR and T2DM (49). In the current study, miR-199a-3p expression was increased following TNF- $\alpha$ or IL- 6 exposure and reached the maximum 
at $8 \mathrm{~h}$, further indicating an association between miR-199a-3p and pro-inflammatory adipokines in the development of obesity-associated IR.

It is well-known that an increase in basal lipolysis is observed and results in the increased free fat acid release during obesity (50). The excess free fatty acid in circulation induces ectopic accumulation in non-adipose tissues and, in turn, alters the secretory pattern of adipose tissue (51). Increased free fatty acid level may lower insulin sensitivity, resulting in IR and T2DM development (52). In the present study, miR-199a-3p increased significantly at $8 \mathrm{~h}$, though this decreased over time. This observation may indicate the negative role of miR-199a-3p in the regulation of insulin sensitivity of adipocytes.

miRNAs modulate genes expression by specifically binding to the 3'-UTRs of target mRNAs. By usage of online tools including TargetScan (www.targetscan.org), miRanda (www. microrna.org) and miRDB (www.mirdb.org), three candidate genes were selected for further research. These were NLK (nemo-like kinase), VAMP3 (vesicle associated membrane protein 3) and Cdk7 (cyclin-dependent kinase 7), which are reported to be associated with obesity, adipocyte differentiation and IR (53-55). However, the association between the potential target mRNAs and miR-199a-3p requires further validation by luciferase reporter assays.

In conclusion, the present study identified miR-199a-3p as an obesity-associated miRNA induced during adipocyte adipogenesis. The effective response of miR-199a-3p expression to different adipokines and FFAs in mature adipocytes indicated it was associated with obesity-associated IR. However, additional studies are required to elucidate the role of miR-199a-3p in adipogenesis and its contribution to the development of obesity.

\section{Acknowledgements}

The present study was supported by grants from the National Key Basic Research Program of China (grant no. 2013CB530604), the Key project of the National Natural Science Foundation of China (grant no. 81330067), the National Natural Science Foundation of China (grant nos. 81300683, 81300706 and 81500649), the Program for Innovative Research Teams of Jiangsu Province (grant no. LJ201108), Key Project supported by Medical Science and Technology Development Foundation Nanjing Department of Health (grant nos. YKK13141 and JQX13012).

\section{References}

1. Van Gaal LF, Mertens IL and De Block CE: Mechanisms linking obesity with cardiovascular disease. Nature 444: 875-880, 2006.

2. Dorresteijn JA, Visseren FL and Spiering W: Mechanisms linking obesity to hypertension. Obes Rev 13: 17-26, 2012.

3. Bell JA, Kivimaki M and Hamer M: Metabolically healthy obesity and risk of incident type 2 diabetes: A meta-analysis of prospective cohort studies. Obes Rev 15: 504-515, 2014.

4. Cummings DE and Schwartz MW: Genetics and pathophysiology of human obesity. Annu Rev Med 54: 453-471, 2003.

5. Morigny P, Houssier M, Mouisel E and Langin D: Adipocyte lipolysis and insulin resistance. Biochimie, 2015 (Epub ahead of print).

6. Fasshauer M and Blüher M: Adipokines in health and disease. Trends Pharmacol Sci 36: 461-470, 2015.
7. Bluher M: Adipose tissue dysfunction contributes to obesity related metabolic diseases. Best Pract Res Clin Endocrinol Metab 27: 163-177, 2013.

8. Guilherme A, Virbasius JV, Puri V and Czech MP: Adipocyte dysfunctions linking obesity to insulin resistance and type 2 diabetes. Nat Rev Mol Cell Biol 9: 367-377, 2008.

9. Bartel DP: MicroRNAs: Genomics, biogenesis, mechanism and function. Cell 116: 281-297, 2004.

10. Kusakabe $\mathrm{R}$ and Inoue $\mathrm{K}$ : Developmental regulation and evolution of muscle-specific microRNAs. Semin Cell Dev Biol 47-48: 9-16, 2015.

11. Alvarez-Garcia I and Miska EA: MicroRNA functions in animal development and human disease. Development 132: 4653-4662, 2005.

12. Sun M, Liu XH, Li JH, Yang JS, Zhang EB, Yin DD, Liu ZL, Zhou J, Ding Y, Li SQ, et al: MiR-196a is upregulated in gastric cancer and promotes cell proliferation by downregulating p27(kip1). Mol Cancer Ther 11: 842-852, 2012

13. Jung KH,Zhang J,Zhou C, ShenH, Gagea M,Rodriguez-Aguayo C, Lopez-Berestein G, Sood AK and Beretta L: Differentiation therapy for hepatocellular carcinoma: Multifaceted effects of miR-148a on tumor growth and phenotype and liver fibrosis. Hepatology 63: 864-879, 2016.

14. Thomas H: Diabetes: Enterovirus dysregulates islet miRNAs. Nat Rev Endocrinol 12: 2, 2016.

15. Esau C, Kang X, Peralta E, Hanson E, Marcusson EG, Ravichandran LV, Sun Y, Koo S, Perera RJ, Jain R, et al: MicroRNA-143 regulates adipocyte differentiation. J Biol Chem 279: 52361-52365, 2004.

16. Chen L, Dai YM, Ji CB, Yang L, Shi CM, Xu GF, Pang LX, Huang FY, Zhang CM and Guo XR: MiR-146b is a regulator of human visceral preadipocyte proliferation and differentiation and its expression is altered in human obesity. Mol Cell Endocrinol 393: 65-74, 2014.

17. Gerin I, Bommer GT, McCoin CS, Sousa KM, Krishnan V and MacDougald OA: Roles for miRNA-378/378* in adipocyte gene expression and lipogenesis. Am J Physiol Endocrinol Metab 299: E198-E206, 2010.

18. Martinelli R, Nardelli C, Pilone V, Buonomo T, Liguori R, Castanò I, Buono P, Masone S, Persico G, Forestieri P, et al: miR-519d overexpression is associated with human obesity. Obesity (Silver Spring) 18: 2170-2176, 2010.

19. Williams MD and Mitchell GM: MicroRNAs in insulin resistance and obesity. Exp Diabetes Res 2012: 484696, 2012.

20. Zhu $\mathrm{H}$ and Leung SW: Identification of microRNA biomarkers in type 2 diabetes: A meta-analysis of controlled profiling studies. Diabetologia 58: 900-911, 2015.

21. Nesca V, Guay C, Jacovetti C, Menoud V, Peyot ML, Laybutt DR, Prentki $\mathrm{M}$ and Regazzi R: Identification of particular groups of microRNAs that positively or negatively impact on beta cell function in obese models of type 2 diabetes. Diabetologia 56: 2203-2012, 2013.

22. Shi C, Zhang M, Tong M, Yang L, Pang L, Chen L, Xu , Chi X, Hong Q, Ni Y, et al: miR-148a is associated with obesity and modulates adipocyte differentiation of mesenchymal stem cells through Wnt signaling. Sci Rep 5: 9930, 2015.

23. Yang L, Shi CM, Chen L, Pang LX, Xu GF, Gu N, Zhu LJ, Guo XR, $\mathrm{Ni}$ YH and Ji CB: The biological effects of hsa-miR-1908 in human adipocytes. Mol Biol Rep 42: 927-935, 2015.

24. Wellen KE, Fucho R, Gregor MF, Furuhashi M, Morgan C, Lindstad T, Vaillancourt E, Gorgun CZ, Saatcioglu F and Hotamisligil GS: Coordinated regulation of nutrient and inflammatory responses by STAMP2 is essential for metabolic homeostasis. Cel 129: 537-548, 2007.

25. Kralisch S, Klein J, Lossner U, Bluher M, Paschke R, Stumvoll M and Fasshauer M: Interleukin-6 is a negative regulator of visfatin gene expression in 3T3-L1 adipocytes. Am J Physiol Endocrinol Metab 289: E586-E590, 2005.

26. Shi C, Zhu L, Chen X, Gu N, Chen L, Zhu L, Yang L, Pang L, Guo X, Ji C and Zhang C: IL-6 and TNF- $\alpha$ induced obesity-related inflammatory response through transcriptional regulation of miR-146b. J Interferon Cytokine Res 34: 342-348, 2014.

27. Neville MJ, Collins JM, Gloyn AL, McCarthy MI and Karpe F: Comprehensive human adipose tissue mRNA and microRNA endogenous control selection for quantitative real-time-PCR normalization. Obesity (Silver Spring) 19: 888-892, 2011.

28. Livak KJ and Schmittgen TD: Analysis of relative gene expression data using real-time quantitative PCR and the 2(-Delta Delta C(T)) method. Methods 25: 402-408, 2001.

29. Leal VO and Mafra D: Adipokines in obesity. Clin Chim Acta 419: 87-94, 2013 
30. Fornari F, Milazzo M, Chieco P, Negrini M, Calin GA Grazi GL, Pollutri D, Croce CM, Bolondi L and Gramantieri L: MiR-199a-3p regulates mTOR and c-Met to influence the doxorubicin sensitivity of human hepatocarcinoma cells. Cancer Res 70: 5184-5193, 2010.

31. Gao Y, Milazzo M, Chieco P, Negrini M, Calin GA, Grazi GL, Pollutri D, Croce CM, Bolondi L and Gramantieri L: CD44 is a direct target of miR-199a-3p and contributes to aggressive progression in osteosarcoma. Sci Rep 5: 11365, 2015.

32. Kinose Y, Sawada K, Nakamura K, Sawada I, Toda A, Nakatsuka E, Hashimoto K, Mabuchi S, Takahashi K, Kurachi H, et al: The hypoxia-related microRNA miR-199a-3p displays tumor suppressor functions in ovarian carcinoma. Oncotarget 6: 11342-11856, 2015.

33. Minna E, Sawada K, Nakamura K, Sawada I, Toda A, Nakatsuka E, Hashimoto K, Mabuchi S, Takahashi K, Kurachi H, et al: miR-199a-3p displays tumor suppressor functions in papillary thyroid carcinoma. Oncotarget 5: 2513-2528, 2014

34. Zuk PA, Zhu M, Ashjian P, De Ugarte DA, Huang JI, Mizuno H, Alfonso ZC, Fraser JK, Benhaim P and Hedrick MH: Human adipose tissue is a source of multipotent stem cells. Mol Biol Cell 13: 4279-4295, 2002.

35. Gesta S, Tseng YH and Kahn CR: Developmental origin of fat: Tracking obesity to its source. Cell 131: 242-256, 2007.

36. Boeuf S, Klingenspor M, Van Hal NL, Schneider T, Keijer J and Klaus S: Differential gene expression in white and brown preadipocytes. Physiol Genomics 7: 15-25, 2001.

37. Bluher M and Mantzoros CS: From leptin to other adipokines in health and disease: Facts and expectations at the beginning of the 21st century. Metabolism 64: 131-145, 2015.

38. Jéquier E: Leptin signaling, adiposity, and energy balance. Ann N Y Acad Sci 967: 379-388, 2002.

39. Ahima RS, Prabakaran D, Mantzoros C, Qu D, Lowell B, Maratos-Flier E and Flier JS: Role of leptin in the neuroendocrine response to fasting. Nature 382: 250-252, 1996

40. Considine RV, Sinha MK, Heiman ML, Kriauciunas A, Stephens TW, Nyce MR, Ohannesian JP, Marco CC, McKee LJ, Bauer TL, et al: Serum immunoreactive-leptin concentrations in normal-weight and obese humans. N Engl J Med 334: 292-295, 1996.

41. Müller G, Ertl J, Gerl M and Preibisch G: Leptin impairs metabolic actions of insulin in isolated rat adipocytes. J Biol Chem 272: 10585-10593, 1997.
42. Steppan CM, Bailey ST, Bhat S, Brown EJ, Banerjee RR, Wright CM, Patel HR, Ahima RS and Lazar MA: The hormone resistin links obesity to diabetes. Nature 409: 307-312, 2001.

43. Chen BH, Song Y, Ding EL, Roberts CK, Manson JE, Rifai N, Buring JE, Gaziano JM and Liu S: Circulating levels of resistin and risk of type 2 diabetes in men and women: Results from two prospective cohorts. Diabetes Care 32: 329-334, 2009.

44. Sheng CH, Di J, Jin Y, Zhang YC, Wu M, Sun Y and Zhang GZ: Resistin is expressed in human hepatocytes and induces insulin resistance. Endocrine 33: 135-143, 2008.

45. Akira S, Taga T and Kishimoto T: Interleukin-6 in biology and medicine. Adv Immunol 54: 1-78, 1993.

46. Lai $Y$ and Dong C: Therapeutic antibodies that target inflammatory cytokines in autoimmune diseases. Int Immunol 28: 181-188, 2016.

47. Hotamisligil GS, Shargill NS and Spiegelman BM: Adipose expression of tumor necrosis factor-alpha: Direct role in obesity-linked insulin resistance. Science 259: 87-91, 1993.

48. Roytblat L, Rachinsky M, Fisher A, Greemberg L, Shapira Y, Douvdevani A and Gelman S: Raised interleukin-6 levels in obese patients. Obes Res 8: 673-675, 2000.

49. Eder K, Baffy N, Falus A and Fulop AK: The major inflammatory mediator interleukin-6 and obesity. Inflamm Res 58: 727-736, 2009.

50. Boden G: Role of fatty acids in the pathogenesis of insulin resistance and NIDDM. Diabetes 46: 3-10, 1997.

51. Gustafson B, Gogg S, Hedjazifar S, Jenndahl L, Hammarstedt A and Smith U: Inflammation and impaired adipogenesis in hypertrophic obesity in man. Am J Physiol Endocrinol Metab 297: E999-E1003, 2009.

52. Boden G: Obesity, insulin resistance and free fatty acids. Curr Opin Endocrinol Diabetes Obes 18: 139-143, 2011.

53. Pei YF, Zhang L, Liu Y, Li J, Shen H, Liu YZ, Tian Q, He H, Wu S, Ran S, et al: Meta-analysis of genome-wide association data identifies novel susceptibility loci for obesity. Hum Mol Genet 23: 820-830, 2014.

54. Maier VH, Melvin DR, Lister CA, Chapman H, Gould GW and Murphy GJ: v- and t-SNARE protein expression in models of insulin resistance: Normalization of glycemia by rosiglitazone treatment corrects overexpression of cellubrevin, vesicle-associated membrane protein-2 and syntaxin 4 in skeletal muscle of Zucker diabetic fatty rats. Diabetes 49: 618-625, 2000.

55. Helenius K, Yang Y, Alasaari J and Mäkelä TP: Mat1 inhibits peroxisome proliferator-activated receptor gamma-mediated adipocyte differentiation. Mol Cell Biol 29: 315-323, 2009. 